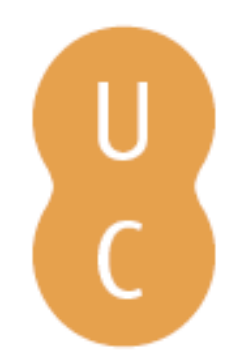

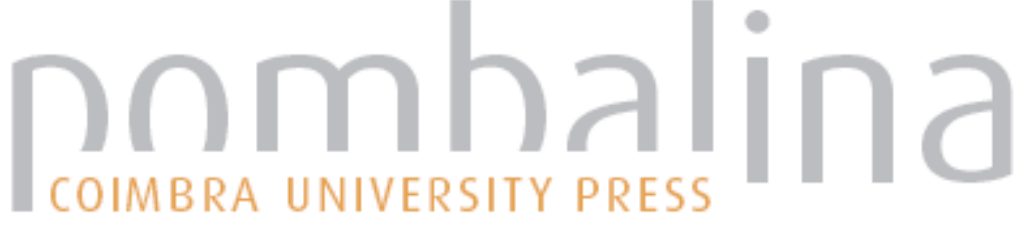

\section{A ama: um motivo clássico no Rancor de Hélia Correia}

Autor(es): $\quad$ Silva, Maria de Fátima

Publicado por: Imprensa da Universidade de Coimbra

URL

persistente:

URI:http://hdl.handle.net/10316.2/32320

DOI:

DOI:http://dx.doi.org/10.14195/978-989-26-0391-9_8

Accessed : $\quad$ 26-Apr-2023 12:36:19

A navegação consulta e descarregamento dos títulos inseridos nas Bibliotecas Digitais UC Digitalis, UC Pombalina e UC Impactum, pressupõem a aceitação plena e sem reservas dos Termos e Condições de Uso destas Bibliotecas Digitais, disponíveis em https://digitalis.uc.pt/pt-pt/termos.

Conforme exposto nos referidos Termos e Condições de Uso, o descarregamento de títulos de acesso restrito requer uma licença válida de autorização devendo o utilizador aceder ao(s) documento(s) a partir de um endereço de IP da instituição detentora da supramencionada licença.

Ao utilizador é apenas permitido o descarregamento para uso pessoal, pelo que o emprego do(s) título(s) descarregado(s) para outro fim, designadamente comercial, carece de autorização do respetivo autor ou editor da obra.

Na medida em que todas as obras da UC Digitalis se encontram protegidas pelo Código do Direito de Autor e Direitos Conexos e demais legislação aplicável, toda a cópia, parcial ou total, deste documento, nos casos em que é legalmente admitida, deverá conter ou fazer-se acompanhar por este aviso. 
Maria de Fátima Sousa e Silva

Coordenação

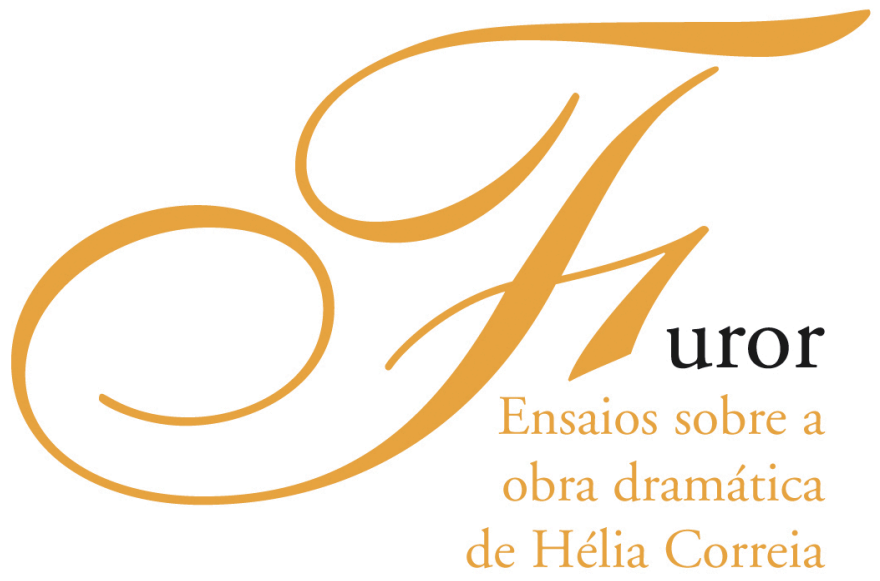

- COIMBra 2006 
COORDENAÇÃO EDITORIAL

Imprensa da Universidade de Coimbra

URL: http//www.imp.uc.pt

\author{
CONCEPÇÃO GRÁFICA \\ António Barros \\ PAGINAÇÃO \\ Inova \\ EXECUÇÃO GRÁFICA \\ Inova - Artes Gráficas \\ Porto
}

ISBN

972-8704-94-1

DEPÓSITO LEGAL

247166/06

C OUTUBRO, 2006, IMPRENSA DA UNIVERSIDADE DE COIMBRA

OBRA PUBLICADA COM O APOIO DE:

Centro de Estudos Clássicos e Humanísticos

FCT Fundação para a Ciência e a Tecnologia

MINISTÉRIO DA CIÊNCIA, TECNOLOGIA E ENSINO SUPERIOR Portugal 
Maria de Fátima Sousa e Silva

Coordenação

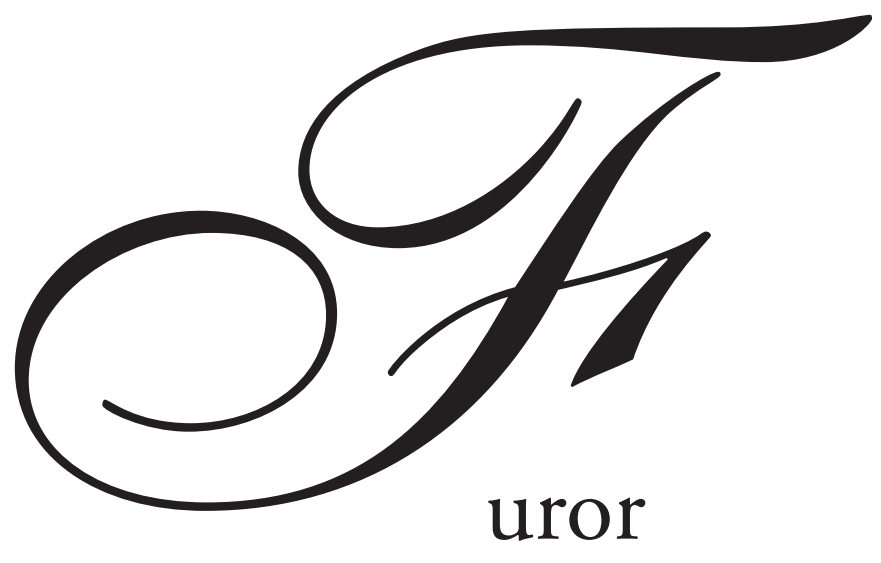

\author{
Ensaios sobre a \\ obra dramática \\ de Hélia Correia
}



Maria de Fátima Silva

Universidade de Coimbra

\section{A AMA - UM MOTIVO CLÁSSICO NO RANCOR DE HÉLIA CORREIA}

Premiada e aplaudida antes de mais como criadora de romance, Hélia Correia dedicou ao teatro dois textos, ambos inspirados na tradição clássica grega: Perdição. Exercício sobre Antígona ${ }^{1}$ e Rancor. Exercício sobre Helena ${ }^{2}$. Nas suas duas produções dramáticas - centradas sobre heroínas no feminino - a Autora dá relevo à figura de uma Ama, para que a tradição clássica lhe não fornece suporte directo; de facto, nem Antígona nem Helena tinham a seu lado, nas versões tradicionais do mito, uma ama a testemunhar ou a partilhar com elas um destino. A tragédia grega, porém, oferece exemplos incontornáveis desta personagem. Depois da criação esquiliana da Ama de Orestes, em Coéforas, foi Eurípides quem aperfeiçoou o recorte deste tipo de figura, de modo a concretizar nas Amas de Medeia e de Fedra os seus paradigmas mais significativos ${ }^{3}$. Para além do apuramento de traços, onde cada um dos poetas investiu com a subtileza da sua sensibilidade, o desenho de uma Ama de tragédia assenta sobre uma estrutura de traves mestras permanentes. A Ama será sempre uma mulher sobre quem os anos pesam já, que acumula a experiência de um longo tempo

\footnotetext{
1 Lisboa, Publicações D. Quixote, 1991.

2 Lisboa, Relógio d'Água, 2002.

3 Aristófanes é o testemunho mais evidente da popularidade destas figuras na cena de Eurípides, que desempenham, em colaboração com as piores tendências femininas, um papel determinante; cf. Th. 340-342, Ra. 1079.
} 
vivido ao serviço de uma mesma família. Da vida dos seus senhores, a Ama conhece cada pormenor e cada crise, que se sucedem como uma linha contínua a ligar, de geração em geração, passado e presente. A proximidade com a casa, selada pelo tempo, torna-a íntima e confere-lhe uma autoridade que é o prémio devido a uma convivência leal. A sua voz comenta, com desassombro e segurança, muito acima do que seria esperável de uma simples serva. Em geral, esta mulher é dotada de espontaneidade e de uma sabedoria popular muito básica, uma e outra inimigas do fingimento e da sofisticação. Se, na casa, alguém existe com quem o relacionamento da Ama seja próximo, esse alguém é a senhora, a cujo serviço a velha criada sempre dispensou o seu esforço. O convívio entre as duas mulheres é, porém, controverso; não lhe falta a compreensão e emotividade que advêm da convivência que as une, como parceiras dentro da condição feminina que lhes é comum, para além de um dia-a-dia partilhado; nem mesmo uma devoção generosa que a serva coloca ao dispor da senhora nas horas de sofrimento e dor. Mas nele pondera também um vago rancor ou concorrência, sempre latente entre criaturas próximas, mas a quem a vida tratou com generosidade diversa. O que a uma sobra em estatuto social e familiar, em riqueza ou em afecto, traduz-se na outra em privação e escravatura. Nas suas simetrias e assimetrias, este é um par dramático de potencialidades infinitas, que a tragédia grega reconheceu e apurou; na produção de Hélia, a mesma tradição gravou uma marca permanente e profunda.

Vamo-nos limitar ao caso do Rancor, onde a Ama de Helena se chama Etra, a velha senhora de Atenas, mulher de Egeu e mãe de Teseu, também ela uma rainha; a tyche, no entanto, não poupou a famosa Etra ao destino de serva de Helena, o mesmo é dizer sua acompanhante e testemunha de tantas aventuras e infortúnios. Vestida das galas da prosperidade e da realeza, uma, e do negro da desgraça a outra, a verdade é que as duas mulheres com facilidade confluem, conduzidas pela mão de uma existência incerta, que a cada dia abala a fronteira insegura a separar senhores de servos, ou felizes de infelizes. A ideia central do Rancor gira em volta do remorso, na procura de uma resposta para o desafio 
que cada indivíduo, como ser autónomo ou dentro de um círculo familiar ou social, tem de enfrentar porque é indissociável da existência: como lidar com as culpas do passado, com todo aquele património que faz de cada um de nós o que somos, que é a nossa identidade, que não podemos alijar, mas que nos pesa, com todas as suas sombras e cobranças em aberto? Como proceder? Saldando dívidas pelo sofrimento e pela expiação? Ou tentando simplesmente arredar fantasmas e reduzir os crimes cobertos da auréola de uma paradigma a meras fragilidades humanas? É esta a aventura que basicamente junta Helena, a causadora de todos os flagelos, com Etra, uma testemunha viva e permanentemente acusadora, voz de um passado sempre presente e próximo, como uma espécie de Erínia ameaçadora.

A cena inspira-se no Canto IV da Odisseia ${ }^{4}$. É dia de recepção na corte de Menelau e de Helena, em Esparta. Telémaco, o filho de Ulisses, ainda à procura do pai ausente, vai ser recebido pelos senhores lacónios. Ao representante de uma segunda geração vai ser dada a possibilidade de mergulhar no universo dos heróis de antigamente e de conviver, ao vivo, com as lendas que lhe estruturaram a imaginação infantil: as glórias do Atrida, os louros cabelos de Helena, a agressividade de Pirro, o filho do supremo Aquiles, entretanto casado com a princesa Hermíone. É neste enquadramento favorável a um encontro do presente com o passado que Telémaco será também apresentado a Etra, de uma forma totalmente inesperada. Como a alguém que, de certo modo, faz parte da família, Menelau destina-lhe alguma atenção: «Ah, não te apresentei a venerável Etra, que tem acompanhado Helena a toda a parte. São na verdade como mãe e filha» (p. 17). Se o anfitrião valoriza a proximidade e o lado afectivo que une senhora e serva, Etra, a complementar a identificação - «Mulher de Egeu. Mãe de Teseu, o salvador de Atenas, o herói» - acentua o estatuto social que as coloca também ao mesmo nível. Tudo concorre para fazer das duas

\footnotetext{
4 Cf. vv. 1-619.
} 
mulheres um par indissociável, constituído por uma criatura humana que se vê sem tréguas perseguida pela sua sombra ou daimon. Esta proximidade foi favorecida pelo tempo, numa caminhada em que Etra acompanhou Helena no seu périplo tradicional, de Esparta até Tróia e de novo no regresso à morada conjugal. Para a exprimir, a peça encontra um símbolo forte e persistente: do atraso de Helena, retida nos últimos retoques de toucador ${ }^{5}$, é a Ama a única a conhecer os motivos (p. 11).

Da sua presença permanente junto de Helena, Etra ganha, no texto dramático, um verdadeiro protagonismo. O seu papel não é o de uma presença secundarizada ao lado da heroína; pelo contrário, a Ama de certo modo sobrepõe-se à senhora, como aliás a todos naquela casa, para quem ela é o porta-voz de um destino que, do alto do seu ascendente, comanda a acção. Tal como a tyche que sempre perseguiu a casa de Micenas é destrutiva, também Etra assume a coloração de uma presença negra e ameaçadora. Para o desempenho deste papel, que parece respirar transcendência, sobram-lhe ainda razões pessoais, que fazem dela uma mão tendencialmente aniquiladora, em nome de um inesgotável ressentimento:

«Etra - Sim, é coisa bem rara uma escrava leal. Sonham com a morte da senhora, as escravas.

Helena - Sobretudo se forem de nobre nascimento e os desastres da guerra as condenaram a servir a mulher do inimigo."

$$
\text { (p. 18) }
$$

Em todo o Acto I, mesmo sob o peso do protocolo de um dia de recepção no palácio de Menelau, o papel reservado a Etra é o do comentário, que lembra, que acusa ou que desmente, rasgando sob a superfície das aparências as cores mais tenebrosas da verdade. Porque não a ligam à família laços de sangue

\footnotetext{
5 A tradição épica deste motivo é testemunhada por Odisseia 4. 121-122.
} 
(p. 33), a velha serva detém a imparcialidade necessária, a par de um testemunho permanente do quotidiano doméstico que a cerca. As palavras que lhe cabem são sempre breves, mas cortantes e irrespondíveis. Vigorosas, pela forma contida como concentram a verdade das denúncias, não deixam margem a qualquer argumentação ou desmentido. Desencadeiam apenas raiva e repúdio, já que os golpes que dão são certeiros e dolorosos, mesmo se justos. Por isso ela é um comentador objectivo, que tem de ser tomado a sério, mas particularmente pungente ${ }^{6}$. Na Helena que dispensa a criada da tarefa de lhe pentear e arrepiar os cabelos (p. 13) se percebe, simbolicamente, um primeiro sinal de repúdio face à dor causada pela intervenção de Etra. A cabeleira da rainha de Esparta é, em toda a peça, a expressão da beleza, do fascínio e do poder sedutor que possui. É sobre ela que a Ama imprime uma violência directa; mas porque afastada da tarefa limita-se à palavra, não menos arrepiante do que qualquer escova de pentear.

Helena é, acima de todos, o objecto principal das suas atenções. Em cada momento da sua saga, Etra assinala as cores mais fortes da sua personalidade ou intervenção. A escolha de Menelau entre tantos pretendentes a cercarem a filha de Tíndaro não passou de uma má estratégia de consorciar irmãos com irmãs: «Sempre foi voz corrente que casarem dois irmãos com mulheres irmãs a nenhum deles trará felicidade. E então com gémeas, tu e Clitemnestra ...» (p. 17). Mais tarde, a permissividade de Esparta na exposição social das suas mulheres ${ }^{7}$ franqueou o acesso ao sedutor troiano, que encontrou no despudor natural e consentido da soberana um interlocutor ideal: «Nem um véu. Nem

\footnotetext{
6 A atribuição à Ama do papel de compreender, de ser capaz de interpretar os sentimentos mais íntimos ou ocultos da sua senhora é reiteradamente expressa em Eurípides (cf. Hipp. 208-211, 224$227,232-238)$.

7 A mesma permissividade de Esparta em relação à intervenção da mulher em sociedade espelhase, no texto de Hélia, no próprio enquadramento cénico do Acto I. O monarca adia o início do cerimonial de acolhimento dos seus visitantes, para dar tempo a que Helena compareça. Por isso Etra tem oportunidade de denunciar mais uma vez (p. 12): "É a vossa mania de espartanos (...) mostrarem as mulheres. Olha que deu um belo resultado ...».
} 
um véu ela pôs sobre a cara. (...) Se ela tivesse posto um véu, talvez as coisas ...» (p. 29). Como uma voz de sophrosyne Etra aconselhou, advertiu; mas sem sucesso, porque afinal Afrodite, como um verdadeiro fatum para Helena, tinha já oferecido a Páris a mais bela das mulheres. Quando a guerra, desencadeada pelo rapto, vitimou também o seu causador, o filho de Príamo, Helena passou para as mãos de Deífobo, outro filho do soberano de Tróia, incapaz de permanecer sem marido (pp. 22-23). Esta leviandade que caracteriza a que foi mulher de muitos homens (cf. p. 30) foi, por fim, a responsável por um ódio geral em sua volta, em resultado de muitas lágrimas e sofrimentos, de que Etra se faz o eco permanente (p. 41): "Que se retire da sala pode ser. De onde não se retira é dos sonhos que juntam as gregas e as troianas, os sonhos do grande ódio por Helena. São tantos sonhos, tantos, que escurecem mesmo as noites de lua, e gemem, gemem. Podem julgar que é temporal, negro e uivante, mas não. São pesadelos de mulheres".

Para além da rainha, que merece a cada momento a censura agressiva da Ama, também Menelau não é poupado, como o representante actual de uma família maldita e o símbolo vivo dos heróis de antanho. Neste diálogo com o passado, é posto a nu o vazio sobre que se constrói a fama e o poder do combate como terreno propiciador de glória. Este que é um pensamento profundamente euripidiano ${ }^{8}$ vem com frequência ao de cima neste Acto I do Rancor. Perante os esforços do senhor de Esparta que, na tentativa de repor o ascendente tradicional da casa a que pertence, repete a grandeza da sua estirpe em fórmulas mais ou menos vazias - "filho e neto de rei, que ninguém esqueça», p. 13 -, Etra debita a memória sanguinária e criminosa de «um banquete em que o pai come os filhos guisados», que se não pode separar da mesma genealogia. Dos Atridas, a geração seguinte desta família malfadada, a fama guardou os galardões do triunfo obtido em Tróia. Mas também neste caso a vitória suscitou

\footnotetext{
8 Expresso com particular acuidade em Helena.
} 
reservas e não foi límpida a luz que anunciou o sucesso. O que Menelau saúda como "a conquista de Tróia», exprime-o Etra, com uma sugestiva correcção, como «O massacre de Tróia» (p. 12). Se o custo excessivo denigre o que se quer celebrar como uma façanha, também a arete que se empenhou nessa luta oscila, susceptível de várias leituras, entre ideais elevados e meros expedientes (p. 22). À pergunta do jovem Telémaco, de visita à corte de Menelau, sobre os trunfos em que se alicerçou a grande vitória dos Gregos e a time dos seus mais distintos heróis, Etra responde com a ganância que é o estímulo das almas vulgares: "Telémaco - Como se ganhou Tróia? Com combates. Não. Com inteligência». "Com traição", comenta Etra. Restam ainda, na configuração convencional da saga troiana, os regressos adiados dos vencedores a caminho do palácio onde a sua reintegração nem sempre é benvinda. Quando Telémaco suspira diante da infelicidade actual de uma Ítaca sem Ulisses, logo Etra lhe contrapõe situações ainda mais dolorosas (p. 30): «Sem falar de Micenas. Que tragédia! Faz a inveja de qualquer cidade». Da rejeição dos legítimos detentores do poder, no seu regresso, dá conta a traição assassina de Clitemnestra; mas, na sombra, outros colhiam do crime dividendos cobardes, como Menelau, enfim livre da eterna concorrência do irmão e um senhor, em tempos de paz e glória (pp. 66-67).

Etra tem, pois, por missão contrapor-se a todos os membros de uma família caótica, que lhe compete punir e desmascarar, em cada gesto que fazem para ocultar as nódoas profundas de um passado de crime, sob um exterior de superioridade e brilho. Todos a olham com ira e tentam calá-la, que é o mesmo que querer calar a voz do passado. O contraste é profundo entre o azedume das reacções à verdade que fala pela boca de Etra, e aquele tom adocicado com que se retoma um cerimonial de fachada, aristocrático e digno.

Se Etra encarna uma antítese face a um ascendente que se quer construir sobre aparências, o que a torna uma sombra negra a manchar o fulgor de um dia de recepção na corte de Esparta, um outro confronto está latente entre a velha serva e aqueles que fazem da criação da glória a sua profissão: os poetas. Uma e outros tomam sobre os ombros o encargo da preservação da memória. Apenas 
o estilo por que o realizam os separa. Obedecendo a uma estética artificial, os velhos bardos construíram uma ficção heróica, laudatória dos deuses e dos homens do passado. Dentro do objectivo que lhes foi conferido, coube-lhes dar voz às grandes causas e estipular um código de virtudes elevadas, fazendo dos agentes desses episódios paradigmáticos verdadeiros heróis. Mais eficazes do que qualquer outro testemunho são as palavras, aladas, frágeis, mas tocadas pelo sopro mágico da memória. Através da música e da poesia, a glória perdura e a memória prossegue, cumprindo a dupla missão de imortalizar o mérito e de educar o espírito das novas gerações. Enquanto os aedos louvam e douram a memória, Etra confronta-a com a dura realidade, ou seja, redu-la a todo o horror que the esteve na origem. Perante a violência subjacente às histórias do passado, Telémaco suspira pela doçura do esquecimento (p. 25): «Ah, que histórias terríveis. Possam fazer os deuses com que os homens as esqueçam no tempo de uma ou duas gerações». Mas a impedi-lo estão os poetas, que se alimentam desses mesmos excessos e fazem deles o seu pão de cada dia (p. 26): «Com esses linguareiros desses cantores que agora andam por toda a Grécia, com tanta morte, e adultério, e cenas de braveza guerreira para porem nos seus versos, nunca mais, nunca mais estas coisas verão o esquecimento». Remetidos para um tempo já lendário, os velhos episódios, por mais violentos e vergonhosos que tenham sido, ganham, nas asas da imaginação e pelo poder da palavra, uma nova face. Cada um os narra à sua maneira; do mesmo sucesso vencedores e vencidos terão cada um a sua versão (p. 38): «Parece que os vencidos desenvolvem uma estranha aptidão para a mentira. Espantosa falta de rigor a deles». Mas se, da parte dos intervenientes próximos, cada um imprime neles o estigma das suas próprias experiências ou emoções, o que não dizer daqueles que dos factos apenas colheram o eco distante, vagos relatos ou tradições difusas, sobre que erguem, por prodígio de um talento criativo, um bastião de glória. É com ironia que Etra põe fim a um espectáculo de fraquezas e agressões entre os senhores de Esparta, despedindo um Telémaco surpreendido que vê desmoronar-se a grandeza de um mito com que sempre conviveu (p. 38): 
«Não tens sono? Não viste já tudo o que querias ver? Já conheceste dois heróis de Tróia. Já te sentaste aos pés da grande Helena. Se tiveres jeito para versejar, levas matéria para uma epopeia».

Para este Acto I, que se desenvolve como um paralelo sistemático entre um passado, cuja violência se ocultou por detrás de uma cortina de glória, e um presente que busca a marca de um esplendor de referência, Hélia encontra um final significativo. Em volta de uma Helena que comparecera na sala sob o exotismo de uma estranha cabeleira egípcia - talvez à procura de uma outra identidade 9 - erguem-se vozes que reivindicam o direito a olhar, por uma vez que seja, a loura cabeleira que imortalizou a maior das beldades. A rainha de Esparta recusa corresponder a esse desejo, mas as exigências redobram. Cada um, por razões próprias, quer satisfazer esse capricho: Telémaco à procura da Helena das histórias que ouviu contar desde a infância; Menelau no encalço de um prodígio da natureza a que nunca foi capaz de resistir; Pirro, já entusiasmado pelo cheiro a um conflito conjugal iminente. É Etra que barra a Helena o caminho da saída e a encurrala entre a pergunta que lhe atiram e a verdade da resposta: onde estão os loiros cabelos de Helena? É que, pela sua intimidade com a senhora, a Ama é a única que detém o conhecimento da verdade, que até ao apaixonado marido escapou. Um gesto ousado do anfitrião, que quer satisfazer a curiosidade de um hóspede e exibir o seu troféu, e eis que a revelação fere, com uma agressividade inesperada (p. 44): «Antes que

\footnotetext{
9 São conhecidas as fontes que, na Antiguidade, preservaram e exploraram a versão do mito que retinha Helena no Egipto, enquanto em Tróia a guerra, em torno do seu rapto, prosseguia. Cf. Od. 4. 227-230, 351-586; Hdt. 2. 112-120; Stesichor. frs. 15 / 192, 16 / 193 Page; E., Helena, passim. É abundante a bibliografia especializada sobre a matéria, de que sugerimos, e. g.: B. B. Powell (1970), "Narrative pattern in the Homeric tale of Menelaus", TAPhA 101, 419-431; A. M. Komornicka (1991), "Hélène de Troie et son double dans la littérature grecque (Homère et Euripide)", Euphrosyne 19, 9-26; J. Assael (1987), "Les transformations du mythe dans l'Hélène d'Euripide", Pallas 33, 41-54; W. G. Arnott (1990), "Euripides' newfangled Helen", Antichthon 24, 1-18; J. G. Griffith (1953), "Some thoughts on the 'Helena' of Euripides", JHS 73, 36-41; I. E. Holmberg (1995), "Euripides' Helen: the most noble and most chaste", AJPh 116, 19-42; G. S. Meltzer (1994), "Where is the glory of Troy? Kleos in Euripides' Helen", Classical Antiquity 13 (25), 234-255; D. G. Papi (1987), "Victors and sufferers in Euripides' Helen", AJPh 108, 27-40.
} 
Helena, exausta, o possa impedir, ele tira-lhe a cabeleira egípcia e todos têm um sobressalto. Os cabelos de Helena estão completamente rapados». Passado e presente encontravam-se para uma profunda decepção geral: sob o aparato exótico da versão do momento, aos olhos de todos patenteava-se o vazio de um paradigma de excelência que não passava de mito.

Se Etra, neste Acto I, colaborou no desmoronar da lenda de beleza e sedução que Helena representava, no que se lhe segue irá partilhar, com o azedume de sempre mas de forma mais próxima agora, a realidade íntima da sua senhora. A nota cénica de abertura alerta para o facto de, ao aparato superficial do salão, situado ao nível fantasioso do mito, se suceder uma tentativa de apagar a memória de uma realidade que é afinal humilhante e mesquinha (p. 47): «Traseiras do palácio, ou pátio, ou descampado na sua vizinhança. Helena, de cabeça rapada e em farrapos, lava obsessivamente o chão de terra». Neste outro cenário, a que faltam as galas da glória substituídas por uma exibição de remorso, Etra parece perder vigor - talvez porque a sua vítima reivindique uma espécie de autoflagelação - e apresenta-se sob a imagem de um tremendo cansaço e de uma preocupação com a rainha que mais parece um desejo de preservar inteira a sua vítima (p. 47): "Não consigo dormir antes de ter-te aconchegado a colcha, bem o sabes». Mas apesar de a cena, e o comportamento da sua figura central, se ter invertido, não se pense que chegou a hora de a verdade se impor, com uma força irremediável. A Helena que se penaliza não veste bem a pele do remorso e da punição. Quando ensaia lavar as manchas permanentes da sua culpa apenas finge ${ }^{10}$, numa tentativa de revestir outra personalidade (p. 47): «Anda para a cama, vá. Já deste o teu espectáculo. Não está ninguém a ver. Helena, chega.» Não consegue todavia, com os gestos tresloucados,

\footnotetext{
${ }^{10}$ A ideia de que Helena sabe fingir e criar uma imagem convincente do seu sofrimento é amplamente aproveitada por Eurípides na peça a que a mulher de Menelau dá o título. Recordemos o apreço com que o coro saúda a estratégia de Helena para obter de Teónoe apoio e conivência (Hel. 944-945): «São comoventes os argumentos que usas na presente circunstância, como comovente és também tu própria».
} 
convencer a sua sombra. As visões que tem (ou antes, que finge ter) do sangue por sua culpa derramado, Etra desmente-as (p. 48): «Estás a ver tanto sangue como eu. Já não caio nessa história há muito tempo»; o espectáculo de contrição que se esforça por montar é desmentido pela Ama (p. 49): «Tu não tens remorsos, Helena. Tens saudades. Eu própria, às vezes, dou por mim a bocejar. E no entanto nunca experimentei um grandioso destino, desses que dão matéria para os trágicos» ${ }^{11}$. Do mesmo modo que antes Menelau ensaiara uma atitude de grande senhor, conveniente a um herói do passado, Helena ensaia por sua vez um papel de heroína de tragédia. Ambos, porém, sem resultado.

Ao recuar do salão para a intimidade da casa, a acção propicia uma maior intimidade entre as duas mulheres que se conhecem e, na sua experiência conturbada, parecem até fadadas para se compreenderem. Etra deixa de ser uma comentadora para se constituir como uma verdadeira interlocutora. A extensão das falas que lhe são atribuídas desde logo o denuncia. A velha serva tem também, no passado, uma história, de onde avulta o desamor. A ligação que a prendeu a Egeu foi forçada, premeditada pelo dolo, e incólume de qualquer sentimento. O filho que dela nasceu, Teseu, é um herói que estimula o orgulho de qualquer mãe, mas que não foi capaz de poupar a sua às penas da escravidão. E afinal, no fim dessa história infeliz, está simplesmente Helena, também ela uma das amadas do herói de Atenas. A recordar esse episódio, funesto como todos os outros que envolveram uma paixão por Helena, Etra repete, como uma fórmula, a denúncia de um gesto que funciona como símbolo do despudor natural da filha de Tíndaro, causa permanente de tanto infortúnio (p. 49): «Velasses o teu rosto e já ninguém se transtornava de paixão por ti» ${ }^{12}$.

\footnotetext{
$\overline{11}$ A noção muito viva que Helena cultiva de uma glória futura a que o seu nome há-de ficar para sempre ligado é já épica; cf. Il. 6. 354-358. Vemo-la até concorrer, de certa forma, com o próprio poeta ao tecer, no seu bordado, a imagem da conquista de Tróia (Il. 3. 125-129), ou ao descrever, do alto das muralhas de Tróia, o exército invasor (Il. 3. 182-242).

12 Cf. supra pp. 119-120
} 
Estamos prestes a mergulhar de novo a fundo no passado, desta vez guiados por uma nova linha de acção. A legenda que agora rotula cada acontecimento do passado é «maternidade». Como mãe que é, vítima das loucuras de um filho, Etra aponta também o dedo acusador à mãe de Helena, como todas as mães inconsciente e incapaz de reconhecer os perigos de que o seu rebento era portador, na hora de pôr nele os olhos com paixão (p. 49): "A tua mãe devia ter-te marcado o corpo inteiro com ferros à nascença. Mas não: aposto que te olhou embevecida, com a suprema estupidez das mães». Compreensão tanto mais justificada quanto Etra colaborou no mesmo erro, na tolerância com que sempre acolheu as leviandades do filho, quando ele cedia aos encantos de uma adolescente, a já então bela e irresistível Helena. Com a tal «suprema estupidez das mães", Etra apressou-se a imputar-lhe, com desvelos de sogra, todas as culpas do rapto: foi Helena, a sedutora! E entretanto escudava-se na veemência das acusações para não ver: para não ver a leviandade fogosa de um jovem imaturo que se chamava Teseu, e o temor que uma moça ainda inexperiente sentia diante de uma aventura nunca antes vivida. Com o tempo, uma angústia culpada veio ao de cima. Também a senhora de Atenas ensaiou um espectáculo de culpa e assumiu, com empenho, o seu papel: o de serva da vítima do seu desdém e dos seus temores. Seguiu Helena como sua escrava, sem, no entanto, se poupar ao prazer de encarnar, junto dela, a sombra permanente do passado. Helena recorda com clareza (p. 51): «Se eu (...) não tivesse exigido levar-te como escrava, sentir-te-ias muito magoada». Foi a própria Etra quem sugeriu esse preço, como indemnização devida ao rapto da irmã dos Dioscuros; decerto pretendia calar pruridos de consciência, mas quem sabe se também abandonar uma vida de frustrações para seguir Helena, em busca de aventura e sabe-se lá também se de glória ... É neste ponto que as duas se descobrem como visceralmente coniventes: ambas magoadas, desiludidas nos seus amores, incapazes de se conformarem à monotonia da vida, ansiosas por uma experiência digna de fama. 
É precisamente no momento em que as duas depõem armas para rirem em harmonia, rirem desse Menelau medíocre, o paradigma do marido enganado e da humilhação a que as mulheres sujeitam o desamor masculino, que chega Orestes, o matricida. Com ele o tema da maternidade ganha uma outra expansão.

Ao primeiro olhar, o príncipe de Micenas confunde, de modo significativo, as suas interlocutoras. Tão próximas as encontra na sua experiência que, à primeira vista, Orestes percebe o porte nobre de Etra; a Helena, ainda sob os andrajos do remorso que pretende revestir, Orestes dá o papel de mendiga, que recebe esmola da generosidade de uma infeliz rainha. Se Etra fizera, de uma vida ao serviço de Helena, uma espécie de calvário - «ainda agora, eu falava (...) de como não consigo adormecer antes de aconchegar a roupa à ... minha filha», p. 54 -, aconselha agora a Helena pena igual (p. 55): "Cuida tu dele. Para ti, vem a calhar. Não procuravas uma expiação? Põe-no no banho e tenta depois adormecê-lo. Garanto-te que será tarefa de valor, tanto mais que parece difícil de cumprir». Sobre o desamor rápido que o estatuto de marido traz à paixão promissora de um amante, soma-se agora, na experiência da vida feminina, o sofrimento da maternidade. Também esta se pode tornar uma relação tremenda, a que ao amor se associa o ódio. Orestes, Etra e Helena são dessa verdade a prova, cada um a seu modo. A todos se abre um caminho de expiação em procura de uma nova luz. O assassino de Clitemnestra vagueia, como é da tradição, em fuga das Erínias. Etra tentou um papel de Ama dedicada, procurando num outro amor de mãe alguma satisfação. É Helena quem, por sua vez, o esclarece (p. 67): «O teu filho abandonou-te à tua sorte, e tu não lhe perdoas, pois não, Etra? Pegas em qualquer outra criatura para poderes fazer papel de mãe ...». Helena, essa, não se conforma com as compensações de uma rotina medíocre; o prazer e a razão de viver residem, para ela, nos actos extraordinários, na assumpção dos erros e das malquerenças, ou seja, na glória insubstituível de se chamar Helena. Pesadelos «todos os temos. Mas é mais de noite que aparecem, que se deitam em cima de nós para nos esmagar. São as almas de todos os que 
ferimos, mas pesam como ferro, essas malditas. No entanto, o segredo, digo-te eu, é uma boa gargalhada ao acordar e uma chapada de água bem fria na cabeça» (p. 58).

Com este desfecho, a relação ama / senhora caminha, no texto de Hélia, para a clarificação. Descoberta a proximidade existente entre as duas, após uma violência latente em cada palavra ou cada gesto, chegou para ambas a hora da redenção. Etra adoptou o caminho da expiação, bebeu, junto de Helena, um cálice de amargura (p. 82): «Foi então esse crime que expiaste, sempre a meu lado. Sempre com a língua afiada, a provocares-me os nervos para que me não esquecesse de te maltratar. Para a eterna culpada de tantos sofrimentos e tantas mortes resta o prazer inestimável da celebridade. Sem uma boa história, a vida não passa de um tremendo bocejo. E os rancores em sua volta, como calá-los? Para esses Helena tem também uma eficaz magia; é Etra quem o reconhece (p. 57): «É o costume. Vêem-na e perdoam-lhe». 



\section{Série}

\section{Documentos}

Imprensa da Universidade de Coimbra

Coimbra University Press

2006

- $\mathrm{U}$

C • 